\title{
The Dying and Those Who Care for Them
}

\section{Ami Rokach}

York University, Canada

"Corresponding author: Ami Rokach, York University, Canada, E-mail: arokach@yorku.ca

Rec date: Nov 09, 2015, Acc date: Nov 16, 2015, Pub date: Nov 24, 2015

Copyright: $\odot 2015$ Rokach A. This is an open-access article distributed under the terms of the Creative Commons Attribution License, which permits unrestricted use, distribution, and reproduction in any medium, provided the original author and source are credited.

\section{Abstract}

The article reviews the loneliness of those on their deathbed, and the complex and demanding field of palliative care, noting the sources of the stresses and strains that the healthcare workers often encounter. It highlights the needs of patients, the reasons why they and/or their families may hamper palliative care, and mostly- what can be done to deal with, and better yet- prevent, palliative workers' burnout.

Keywords: Patients; Palliative care; Hospice; Death; Caregivers; Selfcare

\section{Loneliness of Dying}

The end-of-life experience encompasses feelings of hopelessness, death anxiety, guilt, and loneliness [1]. The feeling of awaiting death's arrival is common amongst the dying [2]. El-Jawahri et al. in 2014 and Kim et al. in 2013 observed that patients that were aware of their terminal diagnosis and understood the implications of such prognosis rated their quality of life lower and showed significant increase of emotional distress and anxiety $[3,4]$. Patients sometimes use denial of terminal diagnosis and of the illness itself is often used to avoid loneliness. Because of the suffering, the social, and the physical constraints of an illness, feelings of emotional isolation and loneliness set in. Many studies $[1,5,6]$ have highlighted the role of loneliness in end-of-life situations. The dying person feels that no one can truly understand his situation and no one can imagine what it is to die. This is characterized by a feeling of aloneness and loneliness in the face of death. Secondly, as you head towards death, as a terminally ill patient, you start losing your identity and your sense of self. Consequently, whatever made you a unique person starts to disappear from your life and, as a result the dying person may feel a lack of relatedness with their world. This overwhelming loneliness is fuelled by the growing awareness that one may die alone separated from others [2]. The physical limitations and the emotional distress [7] experienced by these terminally-ill patients actively contribute to the progressive isolation from others and eventually to the loss of social interactions, which leads to profound feelings of loneliness [8]. Interestingly, although the majority of ill people wish that they would die at home, surrounded by family and loved ones, the truth -unfortunately - is that most people die alone, in hospital beds [9]. However, even having social support and being surrounded by loved ones does not always protect against loneliness of the dying. Although the dying may wish to conserve their interpersonal relationships intact, healthy people, by nature will fear death and will ultimately avoid any contact with it or with disease $[10,11]$. It is, thus, a difficult task for careers to provide the patient with adequate help and emotional support [2]. The dying often feels that discussing their illness and death is inappropriate with loved ones [2]. As a result, patients feel that they ought to conceal the pain and suffering, while keeping their feelings to themselves. Thus, the ill patient has nowhere to turn to but his mind to face this loneliness. To cope with this loneliness, many terminally-ill patients then retreat into spirituality and faith $[5,6,12]$.

\section{Palliative Care}

In general, palliative care aims to achieve the best possible quality of life for the dying patients and for their families, to assist them in adjusting to the many losses they endured, and may still face, and to provide them with dignified treatment and lowered distress for the rest of their days [13,14]. Van Bommel in 1992 eloquently observed that palliative care provides "physical, emotional, spiritual and informational support to help improve the quality of a person's remaining life, and recognizes the patient and family as the principal decision makers" [15].

Palliative care views death as part of life, and unlike the manner that medicine relates to it, it is not seen as a medical failure. Palliative care aims to make the patient as pain free, and comfortable as possible, while it neither hastens nor postpones death. Palliative care takes a holistic view and integrates the psychological, physical, social and spiritual aspects of a patient's care. It offers a support system that enables and encourages patients to live as actively as possible until death, and helps the family cope [during the patient's illness] with the bereavement; anticipatory and post mortem [13].

\section{The Stresses, Demands and Complexities of Palliative Care}

\section{The patient}

People who are ill and dying may pose particular demands for their careers. The patient may be difficult because of his or her pathology, such as brain tumor/s, cerebrovascular disease, or concurrent illnesses. Medications may exacerbate the situation. Psychological factors and psychiatric disorders may turn the patient into a demanding and difficult person to handle; examples of such factors are anger, mistrust, fear, or depression and paranoia which disrupt theirs and the lives of those close to them. The patients' symptoms which may include gross disfigurement, malodour, poor response to symptom management and somatization may result in a patient who is difficult to care for [16]. 


\section{Needs of the patient}

Rokach and Rokach in 2005 presented a multidimensional model of patients' needs, including the following [17]:

Physical/medical needs - such as pain and symptom management, the need to have a warm and caring environment, and the patient's desire to have, at least some, control and say about their treatment.

Emotional/Psychological needs - such as maintaining a sense of control, searching for meaning, and finding the courage to "let go" and bring closure to one's life.

Social needs - such as the needs to love and to be loved, to forgive or be forgiven, and to sustain trusting and intimate relationships which the patient had or wishes to develop.

Spiritual/ religious needs - having a sense of hope and inner peace, being able to participate in cultural observances and in prayers.

It was observed that the hospice caregiver may have to become a surrogate family to the patient, for it takes a family, dedicated and loyal, to assist in fulfilling so many and diverse needs [18]

\section{Demands of palliative work}

Aside from attending to the patients' physical, medical, emotional and spiritual needs, the palliative careers are, frequently, faced with difficult patients, demanding or even unruly families and they may also experience high levels of stress in dealing with their professional requirements. These include:

- Breaking bad news to the patient's family about the patient's diagnosis and/or prognosis.A

- Coping with the realization that medicine is unable to offer these people a cure.

- Being repeatedly exposed to the death of their patients with whom they may have formed relationships, or just cared about them as human beings.

- Involvement in emotional conflicts with the patients, their families/caregivers, or with other members of the palliative team.

- Absorption of the anger, grief, and despair expressed by the patients and their families.

- Working within the medical system, one's personal belief system about the medical network, teamwork, death and dying may be shaken [16].

People are unique and their experiences of pain and death often defy theories, and logic. Professional carers are taught palliative care theories - and then they have to deal with "real life" situations, which as illustrated above may be quite different [19]. Open caregiver-patient communication is, therefore, of utmost importance.

Remen in 1996 eloquently noted that "the expectation that we can be immersed in suffering and loss daily and not be touched by it, is as unrealistic as expecting to be able to walk through water without getting wet" [20].

\section{Roles of palliative workers}

\section{Palliative staff was said [21] to fulfil four major roles:}

1. The Bio-medical role - which directs them to focus on the illness, assessment of symptoms, and treatment of physical symptoms.
2. The Social-therapy role - where they endeavor to meet the patient's emotional, social and material needs.

3. The Bureaucratic role - requiring that palliative workers be familiar with the means and rules of the institution through which the staff's work is delivered.

4. The Friendly, informal role - which complements the Bureaucratic role where the worker aims temper the formalities of hospitals.

While physicians, nurses and other professional carers look after ill people whose condition generally improves, hospice workers are "constantly in the presence of intense emotion, sadness, and impending death without the 'dilution' of patients who become cured, or patients with whom it is possible to build up relationships over long periods" [22]. Consequently, and in order to be available to help the dying, and capable of investing themselves physically and emotionally in to their work, palliative carers have an "onus" as Ley and Van Bommell in 1994 put it, to examine their beliefs, feelings, and attitudes about death, the meaning of life, and grief; to care for themselves, and to supplement their work so as to enrich themselves and reduce the possibility of burnout $[18,23]$.

\section{Caring for the carers}

Regardless of one's age, gender, profession or life stage - the palliative worker can succumb to the constant and unrelenting stresses and demands of their professional (on top of their personal) lives. Selfcare, professional rejuvenation and social support are of prime importance, not only as a response to burnout, but better yet - as a way of preventing it. The self-care process needs to attend to, both, the personal and professional domains, by doing, at least some, of the following:

1. Understanding our strengths and weaknesses. That can be done via self-reflection, or through personal therapy and feedback from our friends, family and loved ones. Once that is achieved, we can plan what and how we live our lives, what emotional/ physical/spiritual "work" we still need to undertake, and how can we use our strengths to compensate for our weaknesses.

2. Listening to our inner voice, being aware of our needs and wishes and heeding our intuition, will allow us to recharge, and will promote self-renewal and guard against burnout.

3. Allowing ourselves not to be defined by our work. That will afford us to give ourselves permission to "take a break" from attending to the dying and their families, stop grieving for a while, and "be" rather than "do".

4. Effective time management skills meaning setting limits and boundaries, and remembering that we are not perfect nor should we expect ourselves to behave as if we were. Seeing to it that we take upon ourselves what we can reasonably comfortably fulfill $[13,24,22,16]$.

Brems in 2000 added to the above the following [25]:

1. Practicing healthy personal habits such as adhering to healthy nutrition, enough sleep, and engaging in physical activity.

2. Paying close and continuous attention to our relationships with those who support us. Included here are being empathic, tolerant, and respectful; developing and enhancing our social support network-our families, friends and intimate relationships.

3. Relaxation and centeredness, getting in touch with ourselves and our inner voice can be facilitated by relaxation and meditation. 
Page 3 of 3

4. Getting professional support via networking, supervision and connecting with colleagues.

In this article I have attempted to raise awareness of the loneliness experienced by the dying, and the stresses with which palliative workers are forced to endure. I have amassed, from a variety of sources, ways of preventing burnout but also of promoting what Koff in 1980 described as the most desired stage in professional growth: deep compassion, where the "worker has the willingness and capacity to serve the dying, coupled with a feeling of his own worth that communicates comfort and respect to the dying person" [26].

\section{References}

1. Kuhl D (2011) Exploring the lived experience of having a terminal illness. J Palliat Care 27: 43-52.

2. Kellehear, A. (2014). The inner life of the dying person. Columbia University Press, New York.

3. El-Jawahri A, Traeger L, Park ER, Greer JA, Pirl WF, et al. (2014) Associations among prognostic understanding, quality of life, and mood in patients with advanced cancer. Cancer 120: 278-285.

4. Kim SY, Kim JM, Kim SW, Shin IS, Bae KY, et al. (2013) Does awareness of terminal status influence survival and quality of life in terminally ill cancer patients? Psychooncology 22: 2206-2213.

5. Rokach A. (2007). Coping with loneliness among the terminally ill. Social Indicators Research, 82: 487-503.

6. Sand L, Strang P (2006) Existential loneliness in a palliative home care setting. J Palliat Med 9: 1376-1387.

7. Miovic M, Block S (2007) Psychiatric disorders in advanced cancer. Cancer 110: 1665-1676.

8. Rokach A, Findler L, Chin J, Lev S, Kollender Y (2013) Cancer patients, their caregivers and coping with loneliness. Psychol Health Med 18: 135-144.

9. Tang, S.T, and Chen C. (2012). Place of death and end-of-life care. In J. Cohen \& L. Deliens (Eds.), A public health perspective on end of life care (pp. 21-34). Oxford, Oxford University Press, New York.

10. Cataldo JK, Jahan TM, Pongquan VL (2012) Lung cancer stigma, depression, and quality of life among ever and never smokers. Eur J Oncol Nurs 16: 264-269.
11. Fife BL, Wright ER (2000) The dimensionality of stigma: a comparison of its impact on the self of persons with HIV/AIDS and cancer. J Health Soc Behav 41: 50-67.

12. Vance D.E. (2006). Spirituality of living and aging with HIV: A pilot study. Journal of Religion, Spirituality \& Aging, 19: 57-74.

13. Faull C. and Woof R. (2002). Palliative care: An Oxford core text. Oxford University Press. , New York.

14. Tang ST, McCorkle R, Bradley EH (2004) Determinants of death in an inpatient hospice for terminally ill cancer patients. Palliat Support Care 2: 361-370.

15. Van Bommel, H. (1992). Dying for care: Hospice care or euthenesia. NC Press, Toronto.

16. Twycross, R. (2003). Introducing palliative care (4th edition). Oxon, Radcliffe Medical Press, UK.

17. Rokach, A. \& Rokach, B. (2005, May 19). The dying and the living: Caring for the patient and the professional who treats him/her. A paper presented at the 8th annual conference of the Israeli Palliative Medicine Society, Tzfat, Israel.

18. Ley, D.C.H, \& Van Bommel, H. (1994). The heart of hospice. NC Press, Toronto.

19. Parkes, C.M. (1997). Coping with death and dying. In: A. Baum, S. Newman,

20. Remen, R. (1996). Kitchen table wisdom. Riverhead books, NY.

21. Hunt, M. (1991). The identification and provision of care for the terminally ill at home by 'family' members. Sociology of Health and Illness, 13: 375-395.

22. Robbins, M. (1998). Evaluating palliative care: Establishing the evidence base. Oxford, Oxford University Press, UK.

23. Chentsova-Dutton Y, Shucter S, Hutchin S, Strause L, Burns K, et al (2002) Depression and grief reactions in hospice caregivers: from predeath to 1 year afterwards. J Affect Disord 69: 53-60.

24. Oliviere, D. (2002). Learning in palliative care: Stories from and for my journey. In: C. Mason (Ed.) Journey into palliative care: Roots and reflections (Pp. 99- 118). Jessica Kingsley Pub, London, UK.

25. Brems, C. (2000). Dealing with challenges in psychotherapy and counseling. Belmont, CA: Brooks/Cole.

26. Koff, T.H. (1980). Hospice: A caring community. Cambridge, Ma: Winthrop Pubs. of Palliative Care, 27: 43-52. 